\section{Unapologetically patriotic - SMA shines the BJSM spotlight on Australian Research}

\author{
Liam Richard West, ${ }^{1}$ Julie Pham ${ }^{2,3}$
}

As we write this Warm Up for the Sports Medicine Australia (SMA) issue of the British Journal of Sports Medicine (BJSM), elite sport dominates both front and back pages of Australian newspapers. We have international cricket, tennis and both Women's and Men's Australian Football League (AFL) is around the corner. Along side elite sport, participation is rising in community level sport and this puts demands on clinicians who treat these weekend warriors.

\section{TALENT DOWN UNDER}

SMA draws together under one banner all sports medicine, sports science and healthcare professionals who work in elite and community sports settings. SMA plays an active role in educating healthcare professionals and sports-minded community members to help individuals benefit from exercise, activity and competition. To reflect SMA's membership, this BJSM edition includes papers from a broad range of disciplines on topics within both sport and physical activity from Australian authors and institutions.

\section{TO LOAD OR NOT TO LOAD?}

Graduated and balanced loading patterns are key for sporting success at any level, but what about during rehabilitation? We also know that tendons love load, but in upper limb tendinopathy central sensitisation is often a key feature, requiring management above and beyond just a graduated loading regime. University of Queensland's Melanie Plinsinga and colleagues examined somatosensory and physiological profiles in patellar and achilles tendinopathies finding associated pain is mainly due to peripheral sensitisation (see page 284). This inspires confidence that mechanical loading is key in these chronic conditions. But not all loading is good loading for the lower limb. Dr Daniel

\footnotetext{
${ }^{1}$ Olympic Park Sports Medicine Centre, Melbourne, Victoria, Australia

${ }^{2}$ Cottesloe Podiatry Centre, Cottesloe, Western Australia, Australia

${ }^{3}$ Allsports \& Family Podiatry and Physiotherapy, West Leederville, Western Australia, Australia
}

Correspondence to Dr Liam Richard West, Olympic Park Sports Medicine Centre, Melbourne, VIC 3000, Australia; liamwestsem@hotmail.co.uk

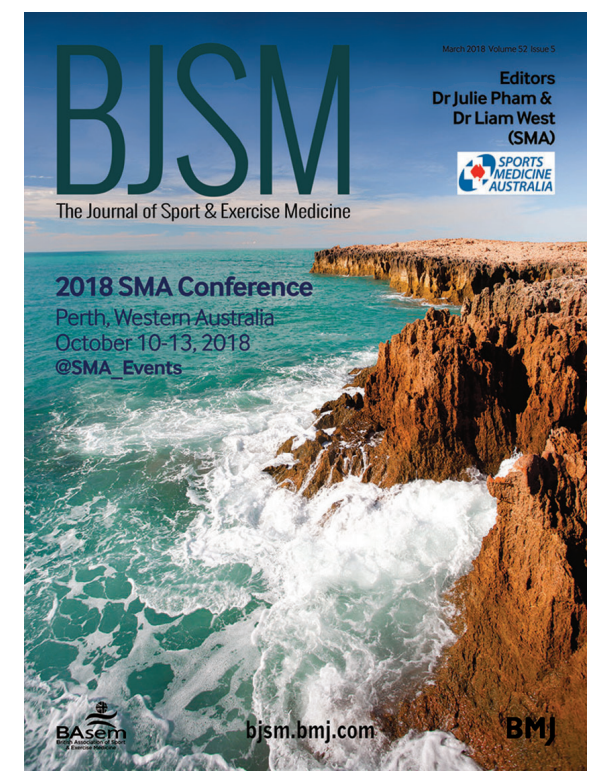

Figure 1 The rugged Western Australian coastline; visit the spectacular southwest after the 2018 Sports Medicine Australia conference in Perth, 10-13 October.

Bananno's group found that prefabricated foot orthoses can help modulate loads and reduce the incidence of lower limb injury in their naval recruit cohort (see page 298).

\section{LESSONS FROM ELITE SPORT}

Even at the elite level of sport with the highest levels of sports medicine input, loading mistakes occur leading to injuries. Canberra's Dr Andrea Mosler, back in her home city after a stint in Qatar, showed that groin pain cost one in five professional football players valuable training and game time loss in a season (see page 292). Prevention of these and other injuries is obviously the Holy Grail in sport. Muscular strength is often used to identify 'weak' athletes at a higher risk of injury. However, the review paper by Brady Green from La Trobe University suggested that the role and application of isokinetic assessment for predicting hamstring strain risk should be reconsidered, particularly given costs and specialised training required (see page 329 ). Staying with hamstrings, the prolific Dr Rod Whiteley and his colleagues (see page 303) identified four daily measures that are useful to track progression of rehabilitation from an acute hamstring strain read the paper to find out which 4 ! But daily physiotherapy measures are not feasible in most community settings. Clinical guidelines often help healthcare practioners progress rehabilitation in settings outside of elite sport. The review paper from Dr Ivan Lin (see page 337) issues caution against blind adoption however, as they found clinical practice guidelines for musculoskeletal pain were of poor quality overall.

\section{THE PHYSICAL ACTIVITY POLYPILL}

While a substantial portion of clinicians' work focuses on injury prevention and management, SMA has a vision to continue to engage with the community and promote physical activity. Ms Katherine Downing and her team (see page 314) emphasise in their review paper that the opportune time to intervene and reduce sedentary behaviour is in early childhood. Physically active children are more likely to remain active into adulthood - why wait until bad health habits have set in to intervene?! We also want to draw your attention to the systematic review paper by Dr Daniel Steffens (University of Sydney) that also hails the benefits of physical activity (see page 344). They found that preoperative exercise halves the postoperative complication rate in patients with lung cancer - what drug could claim to do that!

\section{SPORTS MEDICINE AUSTRALIA CONFERENCE}

What's next? We invite you to attend our National conference in Perth, 10th-13th October 2018 (figure 1). Reflecting SMA's membership, this conference truly has a multi-disciplinary focus with take home messages for all members of the sport $\&$ exercise medicine team. More formally, we aim to promote knowledge and assist in the prevention of lifestyle diseases through sports science and sports medicine by providing an interactive educational forum of the highest standard. We hope to see you there!

\section{Competing interests None declared.}

Provenance and peer review Commissioned: internally peer reviewed.

(C) Article author(s) (or their employer(s) unless otherwise stated in the text of the article) 2018. All rights reserved. No commercial use is permitted unless otherwise expressly granted.

\section{Check for updates}

To cite West LR, Pham J. Br J Sports Med 2018;52:283.

Br J Sports Med 2018;52:283

doi:10.1136/bjsports-2018-099123 